\title{
Prediction of the herd somatic cell count of the following month using a linear mixed effect model
}

\author{
J. J. Lievaart, ${ }^{* 1,2}$ H. W. Barkema, † J. van den Broek, ${ }^{*}$ J. A. P. Heesterbeek, ${ }^{*}$ and W. D. J. Kremer* \\ *University of Utrecht, Department of Farm Animal Health, Faculty of Veterinary Medicine, Utrecht, the Netherlands \\ †Department of Production Animal Health, Faculty of Veterinary Medicine, University of Calgary, Calgary, Alberta, Canada
}

\begin{abstract}
An accurate prediction of the average somatic cell count (SCC) for the next month would be a valuable tool to support udder health management decisions. A linear mixed effect (LME) model was used to predict the average herd SCC (HSCC) for the following month. The LME model included data on SCC, herd characteristics, season, and management practices determined in a previous study that quantified the contribution of each factor for the HSCC. The LME model was tested on a new data set of 101 farms and included data from 3 consecutive years. The farms were split randomly in 2 groups of 50 and 51 farms. The first group of 50 farms was used to check for systematic errors in predicting monthly HSCC. An initial model was based on older data from a different part of the Netherlands and systematically overestimated HSCC in most months. Therefore, the model was adjusted for the difference in average HSCC between the 2 sets of farms (from the previous and current study) using the data from the first group of 50 farms. Subsequently, the data from the second group of 51 farms were used to independently assess this final model. A null model (no explanatory variables included) predicted 48 and $59 \%$ of the HSCC within the predetermined range of 20,000 and 30,000 cells $/ \mathrm{mL}$, respectively. The final LME model predicted 72 and $81 \%$ of the HSCC of the next month correctly within these 2 ranges. These outcomes indicate that the final LME model was a valid additional tool for farmers that could be useful in their short-term decisions regarding udder health management and could be included in dairy herd health programs.
\end{abstract}

Key words: prediction, herd somatic cell count, management, monitoring

\section{Received July 22, 2009}

Accepted September 25, 2009.

${ }^{1}$ Corresponding author: jlievaart@csu.edu.au

${ }^{2}$ Current address: E. H. Graham Centre for Agricultural Innovation (an alliance between Charles Sturt University \& NSW Department of Primary Industries), Locked Bag 588, Wagga Wagga NSW 2678, Australia.

\section{INTRODUCTION}

Regular monitoring of SCC traits such as bulk milk SCC (BMSCC) or the arithmetic mean of individual cow SCC, expressed as the average herd SCC (HSCC), is essential to underpin herd-level udder health management decisions (Lievaart et al., 2007a,b, 2009). Furthermore, farmers and their consultants may use information on associations between udder health and management practices, herd characteristics, or seasonal influences as described in various studies (Bradley and Green, 2005; Green et al., 2006; Olde Riekerink et al., 2007). Yet, given the available information on associations between management practices and historical SCC data, an accurate estimation of the effect of an alteration in management or the future HSCC for monitoring purposes is difficult. For that reason, a prediction of the HSCC for the following month would be a valuable supplementary tool to support a decision regarding whether action is necessary and what the possible effect of that action would be.

Research on the prediction of HSCC or BMSCC has focused on predicting if a penalty threshold in a subsequent period will be exceeded. Statistical process control tools were developed to evaluate udder health and provide a more accurate prediction of future performance (Lukas et al., 2005). The capability index developed by Niza-Ribeiro et al. (2004) demonstrated improved accuracy compared with the regular BMSCC data to describe the ability of the herd to comply with the legal standards. Lukas et al. (2008a) studied the ability to predict a BMSCC violation by analyzing the variation using mean and sigma of the retrospective data on different levels of BMSCC. With the outcome, a grid was created that predicted the probability of exceeding the penalty threshold for each level of BMSCC. Lukas et al. (2008b) described a consistency index that used the variation of the BMSCC to assess if a herd was capable of achieving the maximum variation allowed to meet a desired SCC level. Nonetheless, it would be useful for farmers to have an absolute prediction of the HSCC for the following month instead of merely a probability of exceeding a certain threshold. Using the predicted HSCC outcome, action could be taken if the HSCC and 
Table 1. Summary of the variables used in the linear mixed effect model to predict average herd SCC (HSCC) of the following month

\begin{tabular}{|c|c|}
\hline Component & Variables \\
\hline Herd characteristics & $\begin{array}{l}\text { Herd size, average milk yield }(\mathrm{kg} / \mathrm{d}) \text {, average parity, previous HSCC, percentage of cows with a SCC } \\
<50,>51<150,>151<250,>250<500 \times 1,000 \text { cells } / \mathrm{mL} \text { within the previous recording date }\end{array}$ \\
\hline
\end{tabular}

prevalence of subclinical mastitis increased to a level higher than udder health goals. The objective was to determine the accuracy of a linear mixed effect (LME) model that included factors relating to management practices, herd characteristics, and season to predict HSCC for the following month.

\section{MATERIALS AND METHODS}

The basis of our analysis is an LME model that was derived previously (Lievaart et al., 2007b). Data on management practices and individual milk records were collected for a 3-yr period between 2005 and 2007 in a group of 101 Dutch dairy farms, which subsequently were split at random into 2 groups of 50 (hereafter called group 1) and 51 farms (hereafter called group 2 ). The data of group 1 were used to validate the LME model by comparing predictions with the actual HSCC outcome to determine the performance of the model and to detect errors that could be explained by systematic trends in Dutch dairy farming between the period 1992 to 1995 (data used to develop the LME model) and 2005 to 2007 . The original model was modified to take into account any systematic trends. The data of group 2 were used independently to assess the predictive accuracy of this modified LME model. The predictions of HSCC were compared with a null model that determined the baseline prediction of HSCC without including explanatory variables.

\section{Data Collection}

In total, 200 questionnaires were distributed by 5 veterinary practices located in the northern $(\mathrm{n}=2)$, middle $(n=2)$ and eastern regions $(n=1)$ of the Netherlands. Each practice distributed 40 questionnaires among dairy farmers who housed their lactating cows in free-stall barns, participated in a milk recording system with a sampling interval of $4 \mathrm{wk}$, and had cows of the Holstein-Friesian breed. The questionnaire covered management practices and other variables that were included in the LME model of Lievaart et al. (2007b; Tables 1 and 2). The Dutch Breeding Organi- zation (NRS, Arnhem, the Netherlands) provided the monthly DHI data for a period of 3 consecutive years (individual SCC, percentage of fat and protein, DIM, and milk yield) for the farms that completed the questionnaire. The HSCC was calculated as the arithmetic mean of individual cow SCC for each milk recording date (Lievaart et al., 2007a,b). The farms used to generate this new data set were different from those used in the previous study when designing the LME model. Of the 200 questionnaires, 118 (59\%) were returned. Of these 118 questionnaires, 17 were excluded because of missing individual SCC recording (9 farms) or incomplete questionnaires ( 8 farms). The number of returned questionnaires per veterinary practice ranged from 17 to 26. The data of the remaining 101 farms were used to test the capability of the model to predict the HSCC for the following month.

\section{Statistical Analysis, Validation, and Adaptation of the Initial LME Model}

A model used to determine risk factors for HSCC (Lievaart et al., 2007b) using Dutch data from the period 1992 to 1995 (Barkema et al., 1998a,b) was adapted to predict HSCC for the following month:

$$
\begin{aligned}
& \text { HSCC following month }=\text { intercept }+\beta_{1} \\
& \times \text { seasonal effect (following month) }+\beta_{2}
\end{aligned}
$$

$\times$ management practices $+\beta_{3} \times$ herd characteristics

$$
\text { (e.g., SCC data of the current month). }
$$

Table 2 explains the values for each beta.

Statistical analyses were performed using $\mathrm{R}$ software (R Foundation for Staistical Computing, 2005; http:// www.r-project.org/; version 2.2.0). An LME model was designed with HSCC as the dependent variable to assess the contribution of the explanatory variables on HSCC (Pinheiro and Bates, 2000). The explanatory variables in the group seasonal effects, herd characteristics, and management practices were evaluated. This model was fitted for 3 HSCC categories (low, medium, 
Table 2. Management practices of the linear mixed effect model [average herd SCC (HSCC)]

\begin{tabular}{|c|c|c|c|c|c|c|}
\hline \multirow[b]{3}{*}{ Variable } & \multicolumn{6}{|c|}{ HSCC $, \times 1,000$ cells $/ \mathrm{mL}$} \\
\hline & \multicolumn{2}{|c|}{$<151$} & \multicolumn{2}{|c|}{$151-200$} & \multicolumn{2}{|c|}{$>200$} \\
\hline & $\beta$ & $\mathrm{SE}$ & $\beta$ & $\mathrm{SE}$ & $\beta$ & SE \\
\hline Clipping hair of all cows every year & - & - & -8.8 & 2.1 & -8.4 & 3.8 \\
\hline Dry cows not visually checked for mastitis & - & - & - & - & - & - \\
\hline Dry cows visually checked for mastitis every day & -27.7 & 8.1 & - & - & - & - \\
\hline Dry cows visually checked for mastitis every week & -27.6 & 7.6 & - & - & - & - \\
\hline Heifers not visually checked for mastitis & - & - & Ref. $^{1}$ & - & Ref. & - \\
\hline Heifers visually checked for mastitis every day & - & - & -6.3 & 4.2 & -11.5 & 3.4 \\
\hline Heifers visually checked for mastitis every week & - & - & -8.3 & 4.0 & -7.0 & 3.1 \\
\hline Wet premilking treatment & Ref. & & - & - & - & - \\
\hline Dry premilking treatment & -9.1 & 2.6 & - & - & - & - \\
\hline Time after calving milk is added to bulk tank (d) & -2.7 & 0.8 & - & - & - & - \\
\hline Registration of clinical mastitis cases & - & - & - & - & -10.0 & 3.1 \\
\hline Minimal days of treatment of clinical mastitis & - & - & - & - & -5.5 & 1.6 \\
\hline Postmilking teat disinfection in summer & 4.3 & 1.9 & -5.8 & 2.6 & - & - \\
\hline Calves fed milk with high SCC & - & - & 11.1 & 2.5 & - & - \\
\hline Calves fed with fresh milk & 8.9 & 2.1 & - & - & -9.7 & 3.3 \\
\hline Calves fed with milk replacer & - & - & - & - & -7.0 & 3.3 \\
\hline Cows not fed and not locked in head gates after milking in the winter season & Ref. & & - & - & - & - \\
\hline Cows fed and not locked in head gates after milking in winter season & 14.2 & 5.1 & - & - & - & - \\
\hline Cows fed and locked in head gates after milking in winter season & 13.5 & 4.1 & - & - & - & - \\
\hline Cows not fed and not locked in head gates after milking in the summer season & Ref. & & - & - & - & - \\
\hline Cows fed and not locked in head gates after milking in summer season & -13.1 & 4.5 & - & - & - & - \\
\hline Cows fed and locked in head gates after milking in summer season & -18.8 & 3.9 & - & - & - & - \\
\hline
\end{tabular}

Variable

${ }^{1}$ Ref. $=$ referent 


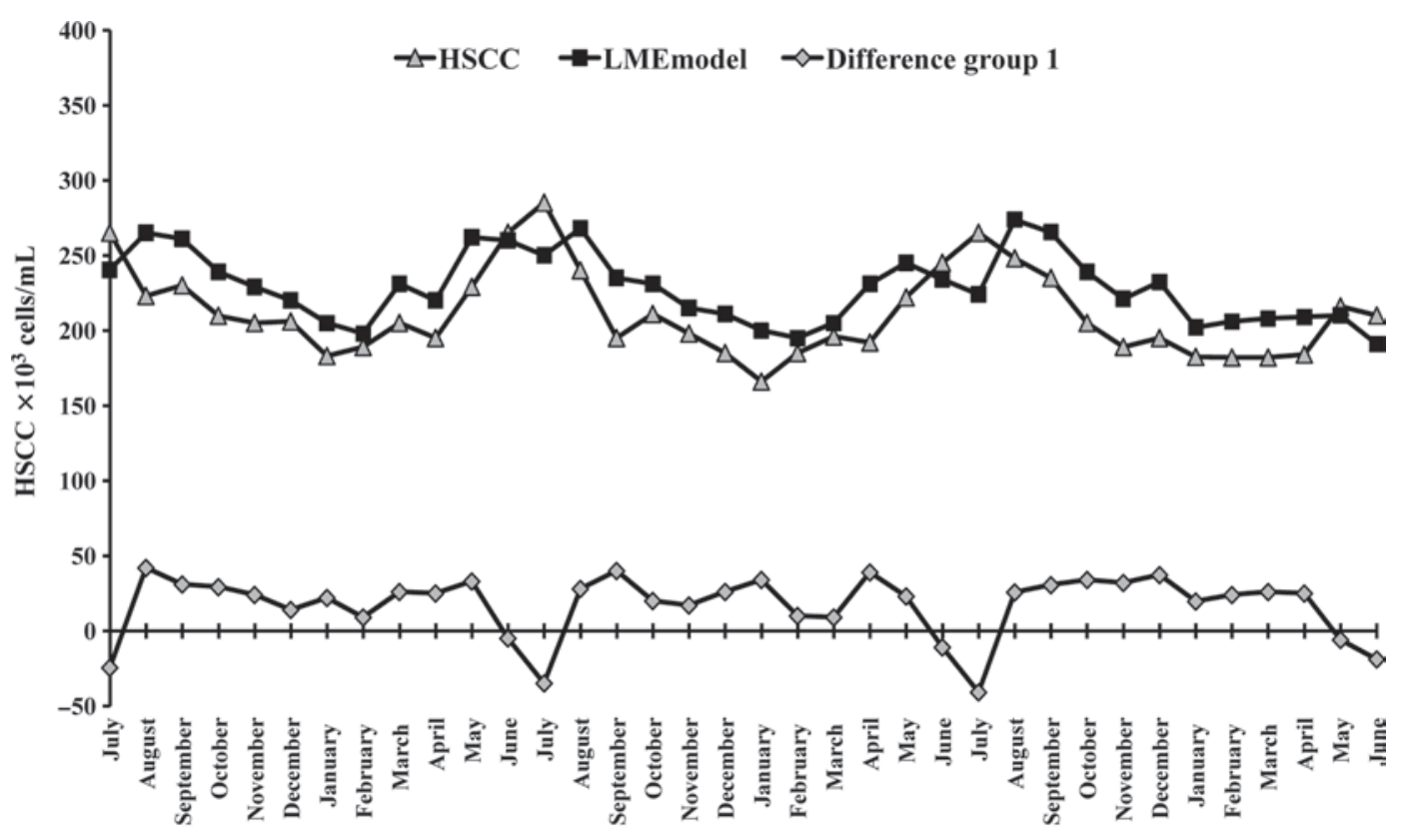

Months in Years 1, 2 and 3

Figure 1. The average monthly herd SCC (HSCC), predicted HSCC, and the difference between the 2 outcomes during yr 1, 2, and 3 based on the initial linear mixed effect (LME) model and data of group 1 (random group of 50 farms to test the initial LME model).

and high) separately (Table 2). The Akaike information criterion (AIC) was used to select the best fitting LME model (Akaike, 1973) using a backward-stepwise elimination procedure. This selection criterion was defined as follows: $\mathrm{AIC}=-2(\log$ likelihood $)+2 k$, where $k$ is the number of explanatory variables (+ intercept) included in the model. The AIC values were then used to compare a series of LME models, and the model with the lowest AIC was considered the best LME model (Akaike, 1973). Because the initial model was based was based on data collected between 1992 and 1995 from a different part of the Netherlands, the LME model [1] was first validated with data from herds in group 1 of the new data set, collected between 2005 and 2007 . The model [1] systematically overestimated HSCC in the more recently collected data, except in June and July, where the model systematically underestimated the data (Figure 1). On the basis of this first validation in the 50 group 1 farms, the initial model [1] was modified to take into account the systematic deviations that could be explained by changes in average HSCC between the 2 data sets used. Therefore, the average of the HSCC value of all farms in group 1 of the most recent data set was subtracted from the average HSCC of the older data collected between 1992 and 1995 and added to the outcome of the model. All management variables that were significantly associated with HSCC in Lievaart et al. (2007b) were included in the model. The data of the 2 groups of farms were analyzed to determine if the adoption of management practices differed between the farms in the 1992 to 1995 and 2005 to 2007 data sets. This analysis was done using either a chi-squared for categorical variables or a $t$-test for continuous variables.

\section{Validation of the Modified LME Model}

The herds in group 1 were used for an independent assessment of this final (modified) LME model. First, the baseline accuracy of the prediction was determined using a null model in which the independent variables of the LME model were not included and HSCC for the following month was assumed equal to the current HSCC value.

Two selection criteria were used to assess the capacity of the LME model in predicting the HSCC for the following month: 1) the percentage of correctly predicted HSCC within a range of 20,000 and 30,000 cells $/ \mathrm{mL}$ of the actual HSCC value; and 2) the mean square prediction error (MSPE) of the model (Rook et al., 1990). The 2 ranges demonstrated the variation in accuracy of the model as a predictor of HSCC. The percentage of correct predictions of the model within the 2 ranges was compared with the predictions made using the null model. The MSPE quantified the amount by which the model differed from the actual HSCC value by providing a value for the exact overall fit instead of predicting within a certain range: 


$$
M S P E=\frac{\sum_{n=1}^{n}\left(H S C C-H S C C_{\text {predict }}\right)_{n}^{2}}{n}
$$

where $H S C C$ is the real value, $H S C C_{\text {predict }}$ is the outcome of the LME model, and $n$ is the number of included data points. The lower the outcome of the MSPE, the better the fit of the model. The overall MSPE was calculated for all farms and clustered per month.

\section{RESULTS}

\section{Accuracy of Initial LME Model}

The AIC values of the initial LME model to predict the HSCC for the following month were $8,236,3,513$, and 7,288 , for the low, medium, and high HSCC categories, respectively. The average HSCC in the 1992 to 1995 data set was 14,000 cells/mL higher than the average HSCC of group 1 in the current study. The average HSCC over the 3 -yr test period of group 1 was 216,000 cells/mL, with a range from 166,000 to 265,000 cells $/ \mathrm{mL}$ (Figure 1). The average predicted HSCC over the same test period was 229,000 cells $/ \mathrm{mL}$, ranging from 191,000 to 279,000 cells/mL (Figure 1). Finally, the average difference between the real and predicted HSCC was 28,000 cells/mL (Figure 1).

When assessing the initial LME model, 60.5 and $73.6 \%$ of the predicted values correctly predicted HSCC within the predetermined range of 20,000 and 30,000 cells $/ \mathrm{mL}$, respectively. The initial model overestimated 29.8 and $18.9 \%$ and underestimated 9.7 and $7.5 \%$ of the actual HSCC values within the predetermined range of 20,000 and 30,000 cells $/ \mathrm{mL}$, respectively. The average overall MSPE was 1,833; the minimum value was 1,032 in January, and the maximum value was 3,161 in August.

\section{Accuracy of Predicting HSCC}

After the difference of 14,000 cells/mL between the average HSCC of the 1992 to 1995 data set and group 1 of the 2005 to 2007 data set was added to the LME model, the accuracy of the model improved. The average HSCC of the second group over the 3 -yr period was 212,000 cells/mL, ranging from 174,000 to 271,000 cells/mL (Figure 2). The predicted average HSCC was 217,000 cells/mL, ranging from 162,000 to 305,000 cells / $\mathrm{mL}$ (Figure 2). The average difference between the real and predicted HSCC decreased from 28,000 cells/mL using the initial LME model in group 1 herds to 8,000 cells/mL using the final model in group 1 herds (Figure 2 ). Compared with the null model, the accuracy of the final model in predicting HSCC increased from 48.0 to $71.6 \%$ (for the 20,000 cells $/ \mathrm{mL}$ range) and 58.6 to $80.9 \%$ (for the 30,000 cells $/ \mathrm{mL}$ range) correctly predicted HSCC values, respectively (Table 3). The final model overestimated $18.6 \%$ and $10.5 \%$ and underestimated $9.8 \%$ and $8.6 \%$ of the actual HSCC within the predetermined range of 20,000 and 30,000 cells $/ \mathrm{mL}$, respectively. The percentage of correct predicted values ranged from $63.6 \%$ in June to $76.3 \%$ in December for the 20,000 cells $/ \mathrm{mL}$ range, and from $71.5 \%$ in June to $88.1 \%$ in January for the 30,000 cells/mL range (Table 3). Simultaneously, MSPE decreased from 2,806 (null model) to 1,114, ranging from a minimum of 747 in November to a maximum of 1,604 in May (Table 3).

Examination of the 1992 to 1995 and 2005 to 2007 data sets revealed that the adoption of 6 management practices were different $(P<0.05)$. The farmers in the second data set (2005 to 2007) more often recorded their clinical mastitis cases (90.9 vs. $27.2 \%$ ), more frequently used postmilking teat disinfection in summer (86.8 vs. $36.5 \%$ ), and locked their cows in the head gates after milking more frequently ( 58.5 vs. $33.8 \%$ ) compared with the farmers of the 1992 to 1995 data set. The farmers in the 2005 to 2007 data set also treated clinical mastitis cases longer ( 3.0 vs. $2.3 \mathrm{~d}$ ), waited longer before they added milk to the bulk tank after calving (4.1 vs. 2.5 d), and did not feed milk with high SCC or antibiotic residues to the young calves as often (30.5 vs. $52.6 \%$ ).

\section{DISCUSSION}

Currently, existing udder health programs monitor SCC data retrospectively and management strategies to correct the situation are implemented when a threshold is exceeded (Schukken et al., 2003; Bradley and Green, 2005). This strategy can create uncertainty on both the outcome of the management strategies and whether the changes that were implemented were necessary. The modified LME model we described predicted 72 and $81 \%$ of the HSCC of the next month correctly within the ranges of 20,000 or 30,000 cells $/ \mathrm{mL}$, respectively. This LME model is a valuable complementary tool for udder health management. Farmers can decide whether changes in their udder health management strategies are needed and then act to prevent an increase of HSCC rather than react to an increase of HSCC after the fact.

The initial model overestimated HSCC and it was adjusted for the differences in the level of HSCC between the period when building the model (1992 to 1995) and predicting HSCC with the data of the first group of 50 farms of the new data set (2005 to 2007). A more appropriate correction would have been one based on the average of the whole population (in this case, 


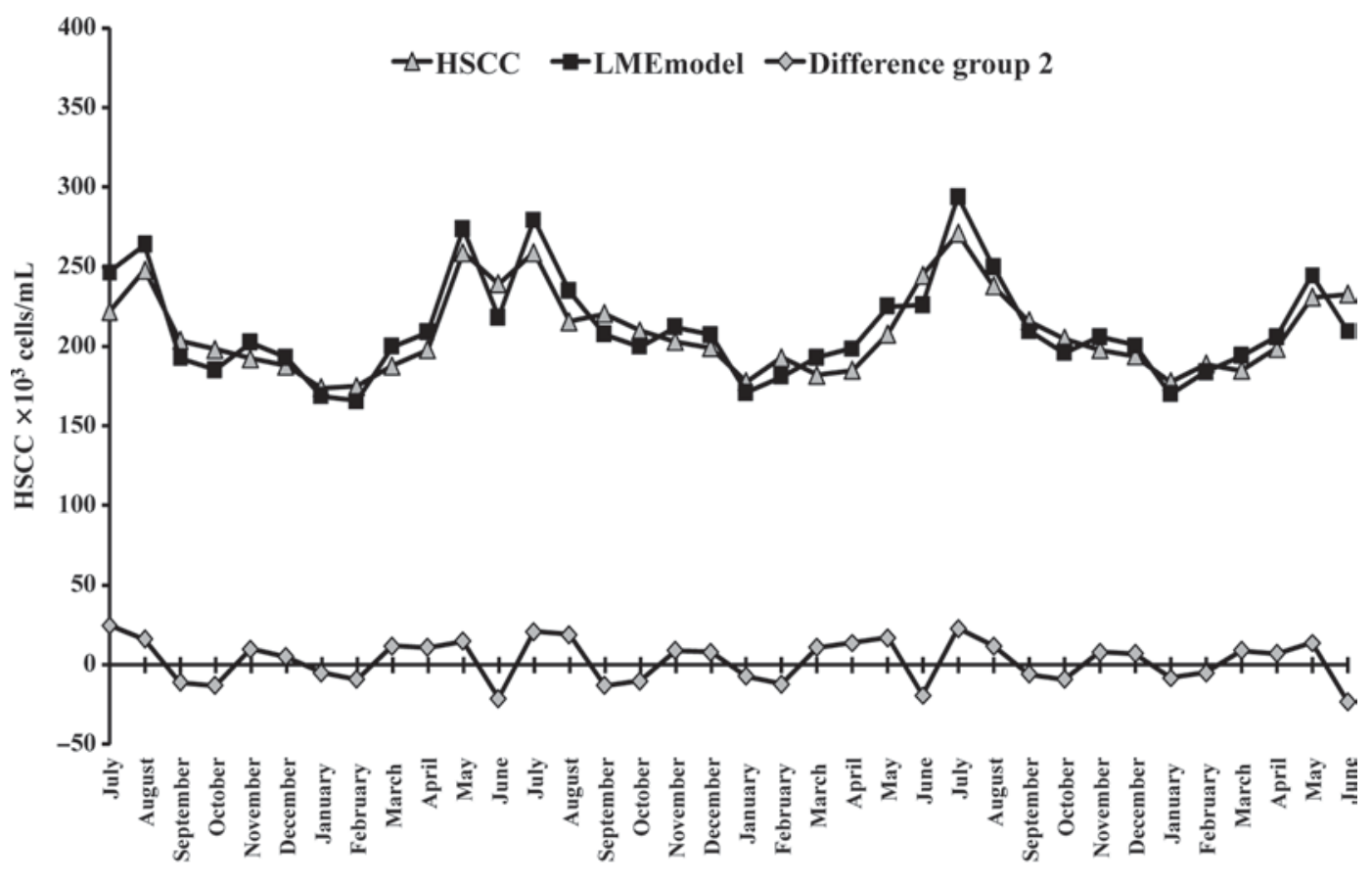

Months in Years 1, 2 and 3

Figure 2. The average monthly herd SCC (HSCC), predicted HSCC, and the difference between the 2 outcomes during yr 1, 2,7 and 3 based on the final linear mixed effect (LME) model and data of group 2 (random group of 51 farms to test the final LME model).

all dairy farms in the Netherlands) or the difference in average HSCC of the 50 farms between the 2 periods 1992 to 1995 and 2005 to 2007 . However, these data (HSCC) were not available, and correction was made by including the difference between the average HSCC values of the 2 data sets. The best comparison was the difference in the level of BMSCC of 18,000 cells $/ \mathrm{mL}$ over the same timeframe (Barkema et al., 2009). The difference in populations of herds indicated that similar corrections for the level of HSCC would be needed when implementing the final model in other regions or countries. To ascertain the utility of the model, the outcome was compared with a baseline model (null model) when only HSCC data were available, and the

Table 3. Average percentage correct predicted outcome and mean square prediction error (MSPE) of a null model (no explanatory variables included in the model) and the final linear mixed effect (LME) model in yr 1, 2, and 3 in group $2^{1}$

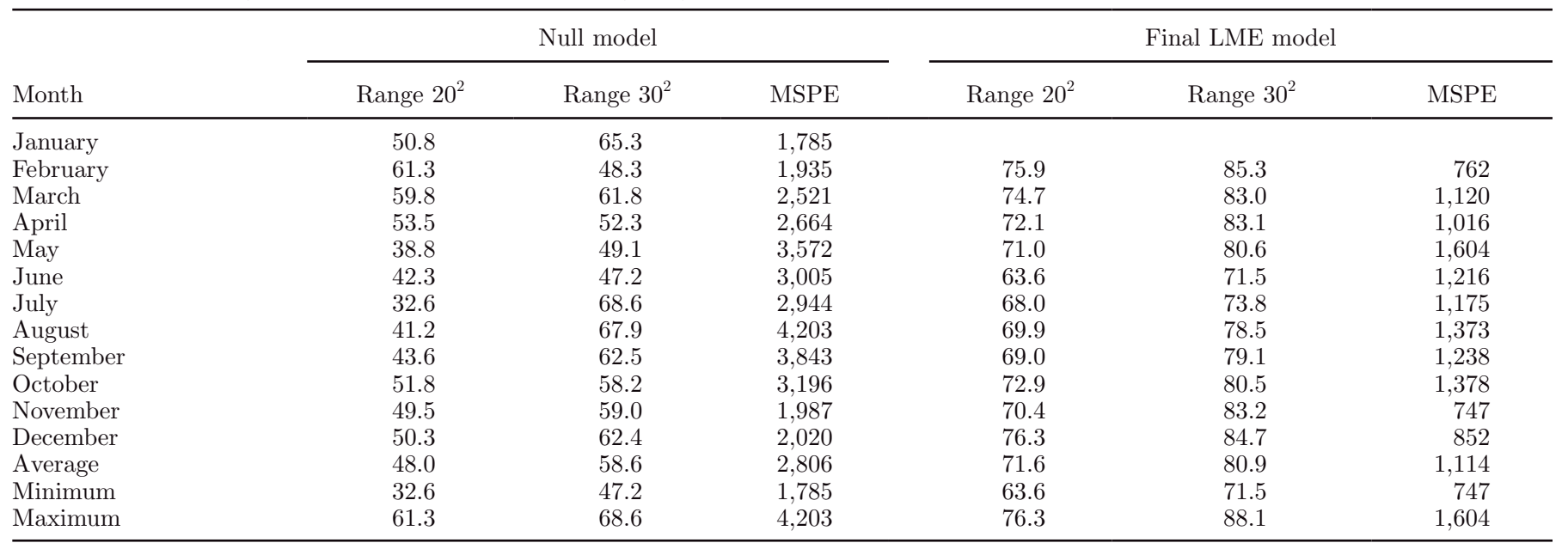

${ }^{1}$ Random group of 51 farms to test the final LME model.

${ }^{2}$ Within the range of 20,000 and 30,000 cells $/ \mathrm{mL}$ of the actual average herd SCC (HSCC). 
best estimation was to assume the HSCC maintains stable within the 20,000 or 30,000 cell $/ \mathrm{mL}$ range of the current HSCC value. Compared with the null model, the modified LME model performed better with 23.6 and $23.3 \%$ in the 20,000 and 30,000 cells $/ \mathrm{mL}$ range of HSCC values, respectively.

A possible reason for the overestimation of the HSCC in the second data set was a difference in adoption of management practices between farms of the 2 data sets used. The contribution of management practices in the final LME model toward the total HSCC varied from $-46,500$ to 27,400 cells $/ \mathrm{mL}$. Farmers in the second data set (2005 to 2007) took a more preventive approach toward udder health and were more aggressive in the treatment of clinical cases. Management practices such as postmilking teat disinfection and locking cows in the head gates after milking were implemented more frequently and clinical mastitis cases were treated longer.

The most noteworthy difference between the current study and previous studies was that the LME model quantified the subsequent predicted HSCC instead of giving a likelihood for the chance of exceeding a defined HSCC threshold (Lukas et al., 2008a,b; Niza-Ribeiro et al., 2004). The extent to which the predicted HSCC exceeded HSCC objectives underpins decisions regarding whether only daily routines need to be revised in the case of a slight increase of HSCC, or whether a major analysis of data and a review of the total farm management is needed in case of a major increase in predicted HSCC.

The accuracy of the model was presented using 2 threshold values for a difference between predicted and actual HSCC, 20,000 and 30,000 cells/mL, because variation in HSCC due to the sampling process would complicate an exact prediction. The level of difference between actual and predicted HSCC that would be acceptable may differ from farm to farm and level of HSCC. Currently, no guidelines exist on how to define the range, with the exception of a study that predicted the incidence of clinical mastitis based on SCC (Berning and Shook, 1992) but that did not include HSCC. The difficulty when choosing a valid range is to determine the capacity of the model to predict within the specified range and the usefulness for practical implementation. If the range is too broad, the model will always predict within that range but will not be useful for practice. A narrow range will provide a very precise model with a low predictive capacity. The range used should be narrow enough to be achievable for the lower values of HSCC but not exceed the lowest HSCC values itself. On the other hand, for the higher levels of HSCC, the range should be large enough to predict whether the HSCC will exceed a penalty limit of 400,000 or 500,000 cells $/ \mathrm{mL}$, thresholds used in most countries in western
Europe and in Canada as a bulk milk quality measure, as was done in other studies (Niza-Ribeiro et al., 2004; Lukas et al., 2008a,b).

The accuracy of the model was assessed using not only the percentage of correctly predicted HSCC, but also the MSPE. This criterion was included to determine the fit of the model as well as a control for the percentage of correctly predicted HSCC values. A large value for MSPE was likely associated with a low percentage of correctly predicted HSCC values and vice versa. Still, this assumption was not always correct. In September, a relatively high percentage of HSCC was predicted within the range, but the MSPE value was relatively high as well (Table 3), suggesting that a high proportion of the predicted values fell just within the chosen range of 20,000 and 30,000 cells/mL of HSCC and therefore qualified as correctly predicted values. In the final model, the outcomes of the MSPE of the 51 farms had lower values that were consistent with the more precise estimation of the HSCC. Nevertheless, in certain months such as May and August, the MSPE values still disagreed with the high percentage of correctly predicted HSCC values, indicating that further refinement of the model was possible. The MSPE measure is an important trait when improving the model and assessing the months that already have a high percentage of correctly predicted HSCC values. On these occasions, although there may be little improvement in the percentage of correctly predicted HSCC, a decrease in the MSPE could indicate that a more precise estimation did occur.

Some suggestions can be made for further improvements of the model. For example, a variable associated with season that was not included was daily temperature. It is possible that inclusion of this variable could provide useful information to the model. This measure could reflect heat stress, which can induce an increase in the individual SCC (Morse et al., 1988; Green et al., 2006). Regarding management, the most important new information from farmers regarding the treatment of subclinical mastitis and culling of high SCC cows (Miller et al., 1988; Bascom and Young, 1998). If information is available about which cows will be treated or culled, an even more accurate model could be developed in the future.

For successful implementation of the model as a management tool on the herd level, 2 issues should be addressed: the collection of the data to feed the model and the feedback of the predicted HSCC to the farmer. The model itself included information on seasonal effects (following month), management practices, and herd characteristics (e.g., SCC data for the current month). The seasonal effects were a unique constant value for each month in the LME model (Lievaart et 
al., 2007b). The herd characteristics will be available from the monthly DHI data, which includes the individual SCC, DIM, and milk yield. The information on management practices could be collected regularly by means of a short survey filled out by the farmer and returned to the DHIA with the milk samples. Finally, the predicted HSCC could be included in the monthly herd report that the DHIA sends to the farmer.

\section{CONCLUSIONS}

The LME model predicted HSCC within a small range of HSCC, is a useful additional tool for shortterm decisions regarding udder health management, and could be included in dairy herd health programs. Information on management practices needed for the model could be collected during herd recording, and the predicted HSCC for the following month can be generated by the farmer in the subsequent herd recording reports. The narrow range of 20,000 or 30,000 cells/ $\mathrm{mL}$ provided the farmer an early warning system for exceeding any BMSCC penalty thresholds. In practice, farmers can use this tool to support or revise treatment and cull criteria of their herd and include this in existing herd health program.

\section{ACKNOWLEDGMENTS}

The authors thank all veterinarians and dairy farmers for their cooperation in the questionnaire and the NRS (Arnhem, the Netherlands) for providing the DHI data.

\section{REFERENCES}

Akaike, H. 1973. Information theory and an extension of the maximum likelihood principle. Pages 267-281 in Second Int. Symp. Inf. Theory. Akademiai Kiado, Budapest, Hungary.

Barkema, H. W., M. J. Green, A. J. Bradley, and R. N. Zadoks. 2009. Invited review: The role of contagious disease in udder health. J. Dairy Sci. 92:4717-4729.

Barkema, H. W., Y. H. Schukken, T. J. G. M. Lam, M. L. Beiboer, G. Benedictus, and A. Brand. 1998a. Management practices associated with low, medium, and high somatic cell counts in bulk milk. J. Dairy Sci. 81:1917-1927.

Barkema, H. W., Y. H. Schukken, T. J. G. M. Lam, M. L. Beiboer, H. Wilmink, G. Benedictus, and A. Brand. 1998b. Incidence of clinical mastitis in dairy herds grouped in three categories by bulk milk somatic cell counts. J. Dairy Sci. 81:411-419.
Bascom, S. S., and A. J. Young. 1998. A summary of the reasons why farmers cull cows. J. Dairy Sci. 81:2299-2305.

Berning, L. M., and G. E. Shook. 1992. Prediction of mastitis using milk somatic cell count, $N$-acetyl- $\beta$-D-glucosaminidase, and lactose. J. Dairy Sci. 75:1840-1848.

Bradley, A., and M. Green. 2005. Use and interpretation of somatic cell count data in dairy cows. In Pract. 27:310-315.

Green, M. J., A. J. Bradley, H. Newton, and W. J. Browne. 2006. Seasonal variation of bulk milk somatic cell counts in UK dairy herds: Investigations of the summer rise. Prev. Vet. Med. 74:293308

Lievaart, J. J., H. W. Barkema, H. Hogeveen, and W. D. J. Kremer. 2009. Reliability of the bulk milk somatic cell count as an indication of average herd somatic cell count. J. Dairy Res. 76:490-496.

Lievaart, J. J., H. W. Barkema, W. D. J. Kremer, J. van den Broek, J. H. M. Verheijden, and J. A. P. Heesterbeek. 2007b. Effect of herd characteristics, management practices, and season on different categories of the herd somatic cell count. J. Dairy Sci. 90:41374144.

Lievaart, J. J., W. D. J. Kremer, and H. W. Barkema. 2007a. Short communication: Comparison of bulk milk, yield-corrected, and average somatic cell counts as parameters to summarize the subclinical mastitis situation in a dairy herd. J. Dairy Sci. 90:4145-4148.

Lukas, J. M., D. M. Hawkins, M. L. Kinsel, and J. K. Reneau. 2005. Bulk tank somatic cell counts analyzed by statistical process control tools to identify and monitor subclinical mastitis incidence. J. Dairy Sci. 88:3944-3952.

Lukas, J. M., J. K. Reneau, and M. L. Kinsel. 2008a. Predicting somatic cell count standard violations based on herd's bulk tank somatic cell count. Part I: Analyzing variation. J. Dairy Sci. 91:427-432.

Lukas, J. M., J. K. Reneau, C. Munoz-Zanzi, and M. L. Kinsel. 2008b. Predicting somatic cell count standard violations based on herd's bulk tank somatic cell count. Part II: Consistency index. J. Dairy Sci. 91:433-441.

Miller, G. Y., M. L. Eastridge, W. D. Hueston, and K. H. Hoblet. 1988. Use of dairy herd improvement somatic cell information by Ohio dairy producers and their perceptions of mastitis. J. Dairy Sci. 71:2284-2291.

Morse, D., M. A. DeLorenzo, C. J. Wilcox, R. J. Collier, R. P. Natzke, and D. R. Bray. 1988. Climatic effects on occurrence of clinical mastitis. J. Dairy Sci. 71:848-853.

Niza-Ribeiro, J., J. P. Noordhuizen, and J. C. Menezes. 2004 Capability index - A statistical process control tool to aid in udder health control in dairy herds. J. Dairy Sci. 87:2459-2467.

Olde Riekerink, R. G. M., H. W. Barkema, and H. Stryhn. 2007. The effect of season on somatic cell count and the incidence of clinical mastitis. J. Dairy Sci. 90:1704-1715.

Pinheiro, J. C., and D. M. Bates. 2000. Mixed effects model in S and S-Plus. Springer, New York, NY.

R Foundation for Statistical Computing. 2005. R: A language and environment for statistical computing, R Development Core Team, Vienna, Austria, http://www.R-project.org

Rook, A. J., M. S. Dhanoa, and M. Gill. 1990. Prediction of the voluntary intake of grass silages by beef cattle. 3. Precision of alternative prediction models. Anim. Prod. 50:455-466.

Schukken, Y. H., D. J. Wilson, F. Welcome, L. Garrison-Tikofsky, and R. N. Gonzalez. 2003. Monitoring udder health and milk quality using somatic cell counts. Vet. Res. 34:579-596. 